\title{
Does the University Third Mission Entail Sustainability Science: Evidence from Indian Higher Educational Institutions' Sustainable Technological Patenting Activity and Collaborations
}

\author{
Lourden Selvamani, P.G. Arul
}

\begin{abstract}
This paper explores the vision of "University Third Mission" on the emergence of "Sustainable Science". We aim to track environmentally sound technologies (ESTs) patent trends, proportionate players, collaborative players of higher educational institutions. The patentscope database and green patent inventory of World Intellectual Property Organisation (WIPO )is utilized to extract patent filings details of Indian Universities and Indian Institutes of Technologies(IITs), thus totally 930 institutions for the period of 14 years. After the cleaning process, data visualization tools and technique like Gephi, are applied on data to check collaboration patterns using centrality measures and excel for charts. We find that overall patenting trends are increasing; yet ESTs patent filings are low. Only a meager number of institutions are active and a handful of institutions have the collaboration record showing the research for sustainability is something to embrace. Status of current research output shall equip the policymakers and university management to design future research agenda and strategies to execute the university third mission and to contribute for sustainable development. This research brings new thoughts on university research for sustainable development and adds value within university third mission; it focuses on Technologies for sustainable development filings, micro level players and their collaboration patterns.

Index Terms: higher education, patent, environmental technology, sustainable technology, third mission, green inventory, sustainability, sustainable science, sustainable research
\end{abstract}

\section{INTRODUCTION}

Expanding the role of universities to cooperate alongside industry and government is acceptably paramount to discharge "University Third Mission", a social initiative and innovation agenda to strategically and consciously benefit the host society, besides teaching and research[42],[19]. Universities play an active role to collaborate with industry predominantly by offering technical support. Interactions extensively happen on the grounds of consultancy, sponsored research, joint research, patenting, licensing, entrepreneurship, academic spinoff etc. for innovation and sustainability [2],[9],[10],[18],[19],[36].

Revised Manuscript Received on October25, 2019

Lourden Selvamani, Research Scholar, Department of International Business, Pondicherry University, Pondicherry, India.

P.G . Arul, Professor, Department of International Business, Pondicherry University, Pondicherry, India.
Being a proactive element in science and technology policies, the knowledge producer embark on an unprecedented powerful mission to create a sustainable future, around worldwide, many academic institutions endorsed the declaration for enabling sustainability since the 1990s[1]. The declared theme focus on the ethical responsibility of universities to contribute towards global sustainability; community outreach programme, educate environmental literacy; commit faculties to carry research aligning sustainability; Fostering a partnership with industry, individual, governmental and non-governmental organisations; inter-university cooperation[1].

India, the fastest growing economy and third biggest energy consumer of about 1.21 billion population, majority rural people and 396 million people do not have access to electricity and about $80 \%$ population depend on combustible biomass fuel for cooking activities. The Indian government faces the crucial challenge to fulfill its energy commitments in the upcoming decade [4], [5], [25]. Government has pitched ensuring programmes to meet rural electrification, road and digital connectivity, expansion of renewable energy. All governments, industries, academicians and experts forge hands for sustainable development goals [4],[8].

The concept of "sustainability" broadly accommodates multiple perspectives [41]. The accountability literally opened up new operations for universities to engage in the rapidly growing field of "Sustainability Science" [17] to add value to the university's third mission through inclusive innovation. Sustainability science is the domain of its own to harness technologies focused on nature and society, science should prioritise vital and change unsustainable research agenda to address sustainability [2], [3]. Triple helix models in universities require government-academia-industry for innovation and sustainable development. The third mission ground on triple helix to strengthen regional and national Innovation system [2], [18]. In [45] Trencher et al. argued the function of Co-creation for sustainable development as extended mission of the university. 


\section{Does the University Third Mission Entail Sustainability Science: Evidence from Indian Higher Educational Institutions' Sustainable Technological Patenting Activity and Collaborations}

Scientific innovations provide excellent prospects for the environment, Therefore on grounds of research for sustainable development perspective; we explore "University Third Mission" reflection on "sustainable Science" or vice versa through innovation agenda and Indian higher educational institutions collaboration between industries and government. The purpose is to present evidence on universities sensibility on innovation for sustainable development of the society and for university sustainability which adds to debate on the third mission and triple helix [45] [18].

Patents, a valuable and easily traceable source of information on innovation for measuring policy impacts [12],[20],[29],[30]. Many researchers explored university patenting activity, patent valuations, citations, deducted drivers behind such activities[20],[21],[27],[29],[40] Few studies utilised bibliometric techniques to measure science and technology linkages between higher educational institutions and research institutes based on data provided by PATSTAT database and USPTO [12]-[14],[28] some confine to particular fields[23],[24],[26]. Only a few exceptional studies investigated patenting activity associated with sustainable development limited to scientific fields and at a macro-level [25],[26],[30]. Detailed analysis of innovations for sustainable development developed by an important element of the national Innovation system within a single hierarchy measured in terms of patents is seldom conducted nor is patentscope database adopted.

To fill this gap and to evidence a study on the university's consciousness on sustainable development in developing countries. Given the significance of higher educational institutions, we felt it is consequential to explore relatively the growth performance of innovative sustainable technologies and level of research collaboration at IITs and universities of India totally 930 institutions, which are reflected in patenting performance and it has been subject of interest for management scholars recently because of reliability, availability of data [20]. Because of the significant requirement of sustainable development for the country, policymakers and management might interested in generated sustainable technologies as an indicator to scale up sustainable future research inclusive innovation policies and practices; in fact many countries are developing alternate appraisal system for practices on sustainability in a university [6]. Our work contributes to the vision of sustainability of institutions through research for sustainable development.

Patent filings on ESTs, considered as an indicator to measure innovation on sustainability. The core theme is to assess the quantity of technological output; patent data extracted from the patentscope database administered by World Intellectual property Organization (WIPO) for the period 1/05/2005 between 31/05/2019 i.e. 14 years. For recognising ESTs, we utilised IPC Green inventory developed by WIPO. The paper explores (i) To analyse the patenting trend inclusive of ESTs patenting collaboration trends; (ii) Identifying prolific institutions (i.e.) Leading creators of sustainable technologies (iii) Determining the proportion of fields of ESTs (iii) Identifying key players in collaborations of patents filings. We resorted Open Refine, the software package to clean patent data, Gephi and Microsoft Excel for data visualization and centrality measures.

The consecutive part of the paper is as follows; section 2 deals with relevant literature and concepts followed by the method adopted from the study. Section 4 throw light on results and section 5 concludes the paper.

\section{LITERATURE REVIEW}

\section{A. University Third mission}

University third mission an encountered consequence of globalisation, institutional competition, innovation demand from government and industry since it also positions universities to impact the economy for more societal engagement and economic development besides teaching and research [7], [11]. In [19] Zomer \& Benneworth studied the emerging university's third mission relationship with institutional reforms, thus posit funding crises, dynamism in knowledge production, recognising innovation as source economic success and concluded commercialising research and engagement are important pillars teaching and research which shifted higher education structure. Third mission along with triple helix universities are envisioned as part of innovation and sustainability, which aided by establishments of technology transfer office, policy support to commercialise intellectual Property rights, business incubators with sole intent to improve regional and national innovation system [9], [18].

Triple helix model operates an interaction between university-industry and government being the regulator, sometimes as a participant. In [36] Ankrah \& Omar produced a systematic review on university-industry collaboration, the organisational forms of interaction are personal informal relationships, personal formal relationships, a third party formal target agreements, formal non-target agreements and focuses structure. Interaction modes are relatively wide which includes patenting, spinoff, sponsored research, consultancy research, etc. However, patents comprehended as the formal target agreement approach which implies an easy source to benefit and plausibly deciding process for technology transfer and commercialisation[20][21]. Sustainability is an evolving one which provides vision to think beyond university third mission [45]. Third mission emerged to enhance the commitment of the university to society; the dynamism has developed to forge many routes to interact with government and industry through technology transfer and commercialization.

\section{B. Research for Sustainable Development}

Sustainable science, a vibrant interrelated domain to monitor how the social change affects the environment, and its movements to harness science and technology for sustainability focus on the dynamic interactions between nature and society for sustainable development [44]. There is no one way of developing sustainability in 
higher education and strikingly there is no one way of viewing sustainability [41]. Therefore, sustainability is a concept without boundary that led to multiple perspectives. From research for sustainable development perspective was defined by [15] Waas et al. as "all research conducted within the institutional context of a university that contributes to sustainable development" a research identified within the walls of university inclusive of basic and applied research aligned to sustainable development irrespective of discipline of research with focusing characteristics like interdisciplinary, action orientation, global aspects, proactive and problem-oriented etc., In [3] Gallopin, Funtowicz, O'Connor and Ravetz posit science performance modifications, to point current research model is unsustainable for economically, socially, and ecologically. As in [2],[15] universities need to contemplate research for sustainable development as full-time exercise rather than a "add-on" and suggest a research framework to be exclusively for adaption. Universities bear intrinsic responsibility to reorient research contribution to solve the sustainability crisis; Adding to this, traditional way of approaching research problems should be delineated and thus develop holistic research approach to address sustainable development. A study that reviewed the commitment and implementation of sustainable development in higher educational institutions keeping research as one of the variable identified notable positive changes throughout the system and strong linkages between the institution's commitments to sustainability [16]. However, achieving sustainability without tension in the pluralistic community is a challenge [41]. Consequently over decade sustainability emerged as a new research domain as "Sustainability Science" with a research framework [17]. A recent Study compared research trends and the United Nations Educational, Scientific and Cultural Organization's (UNESCO's) strategic perspectives and showed most of the research focus on environmental issues [47]. In summary, the vision of sustainability has invoked the activities for universities at all levels, thus research and innovation do not differ from other activities to attain sustainability.

\section{University Patenting Activity}

Growing evidence shows patent activity has increased across universities to commercialise the research since the inception of policy changes [30], [32]. In [20] Baldani observed university patenting differs between universities and differ according to capabilities and scientific specialisations, though patent being an incomplete indicator, yet it is a precondition for the successful technology transfer. In [21] Baldani identified sharing revenue between department and inventor spur more patenting and argued installation of policies for intellectual policy rights. Several authors evidenced motivations to patenting activity [20]- [22]. Ray and Shah [22] concluded faculty background, faculty attitude, research sponsorship and institutional parameters affect the faculties patenting behaviour. In fact, supported by an increase in patenting activities by universities and IITs, though at the nascent stage [12-14]. Many studies have inspected patenting in various fields, for example [23] Studied concussion of re-regulated patent regime and research investments over pharmaceuticals industry patents in India, we find a similar study on biotechnology [24]. In [14]
Sharma \& Jain explored Indian higher education patenting scenario and concluded such activities are at the nascent stage. In summary, patenting activity fairly reflect innovation output of university to validate the response to third mission stimuli.

There are Cases where environmental policies induced more sustainable technology patent counts, exceptional studies in line with our research as in [30] done empirical analysis focussed impact of policies on patenting activities of high-income countries where established policies show, public policies have positive significance over generation renewal energy patents keeping policy proxies, technology-specific expenditure, electricity consumptions and price as an exploratory variable. A holistic study measured the ESTs status based on International Patent classification codes and PATSTAT database which evidenced an exponential increase in green technologies over the decade which highly concentrated in Japan, USA, German and China[25].Another study analysed patent collaboration network of Smart Grid field based on data of State Intellectual Property Office of China, the study found that the central agents like to the development of smart grid field using complex graph theory [26]. However, most of the literature on sustainability in connection to universities has limited to understanding the impact of sustainable development on teaching, environmental management of the institutions and higher education policy analysis [15]. Therefore, the impact of sustainable development on university innovation output apart from publications needs to be unearthed.

\section{METHODOLOGY}

This research followed 4 phases before subject to analysis

1. Retrieving patent applications data from patentscope and data cleaning using open refine (previously Google refine) to clean messy data.

2. Cross verify universities and IITs entries with consolidated university list.

3. Filtering ESTs extracted from green inventory.

4. Applying data visualisation using Microsoft Excels and collaboration network through Gephi.

Step 1: Patent application data were retrieved from patentscope database, a global public patent search system developed by WIPO; which provide accesses to national patent data of selected countries and patent cooperation treaty data up to 10000 records at a time [31]. To Collect patent application data[32], for information retrieval we used search keyword as "university" in applicant name field and set office as "India" to get national patent data in advanced search interface. The patent applications are considered as "university application" when it filed under the name of university or spelling variant or technology transfer offices or any centres of respective universities. The same procedure was followed to collect data on IITs for the period between $1 / 1 / 2005$ to $31 / 5 / 2019$. However, the raw data was subjected to cleaning, thus we adopted open refine previously called as to Google refine for clustering, after correcting spelling variant and typo errors[31]. 


\section{Does the University Third Mission Entail Sustainability Science: Evidence from Indian Higher Educational Institutions' Sustainable Technological Patenting Activity and Collaborations}

Step 2: Patent applications dataset contain Application ID, Country, Application number, Publication date, IPC codes, Applicants (including Co-assignee) and Inventors. The retrieved university names are cross-referred with University Grand Commission (UGC) consolidated universities list [33] i.e. central universities (48) deemed to be universities (126), state universities (399), and private universities (334) as on 31.03.2019 to eliminate foreign entries and followed same for 23 IITs [35]. We consider patent applications as university filings when one applicant being Indian university or IITs. For some entries labels of the IITs are not provided, though we considered for the patent count. The exported patent applications dataset for university contained 1933 records and 2495 records against IITs from 2005 to 2019(up to $31 / 05 / 2019$ ) inclusive of 222 collaborative patent applications of IITs and 273 collaborative patent applications for universities.

Step 3: In 2010 WIPO launched "IPC Green Inventory" which simplified retrieving patent-related information on ESTs as listed by the United Nations Framework Convention on Climate Change (UNFCCC) [34]. Inventory has information on technologies fall under alternative energy production, energy conservation, transportation, waste management, agriculture/forestry and nuclear technologies. Click on the ESTs classification code links in IPC column of green inventory display patent information on patentscope database, however for research convince we collected all ESTs codes from inventory which had over 1000 codes. With the codes we filtered matching IPC codes from exported patent dataset manually; patent entry with at least one ESTs code is considered for the count. From the university dataset, we filtered 109 ESTs patent applications and 151 in case of IITs. Collaborated ESTs patent applications are also filtered.

Step 4: The resulted dataset further processed for data visualisation to find trends; proportion of applicants, proportion of ESTs fields, top players, collaboration relationships using excel \& Gephi for understanding collaboration network [13],[14],[23]-[26],[31],[46]. Centrality measures of the network are analysed to determine important nodes in a network which showed by degree centrality, betweenness centrality, closeness centrality, eigenvector centrality [27],[37]-[39].

\section{RESULTS \& DISCUSSION}

With inception of scientific polices technological innovations were filed and maintained growth [14]. From 2005 to 2019 the patents filed by IITs and universities have together recorded 4428 entries including 6\% (257) of ESTs entailing 22 collaboratively filed patents. Total ESTs filed by IITs counts to 151 whereas universities filed 106.

Fig.1, from 2005 to 2019 number of a patent filed by IITs ballooned, however from 2012 patent filing growth is rapid and in case of ESTs started to gain momentum from same year average annual growth rate $22 \%$, the highest ESTs filed is 29 in the year 2017.

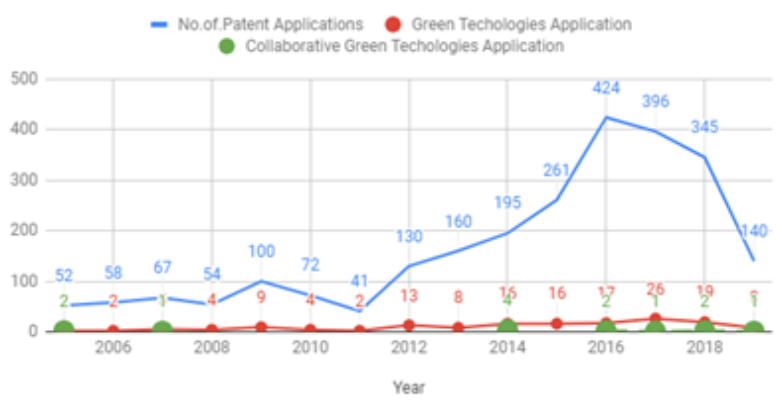

Fig.1: IITs Patent filing trend from $2005-2009$

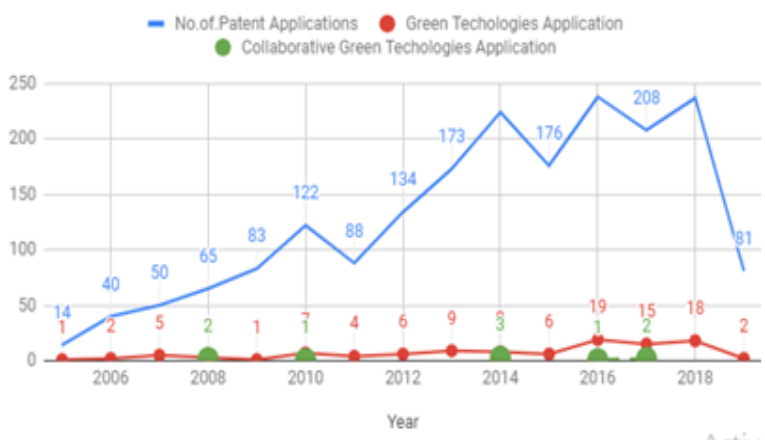

Fig.2: Universities Patent Filing Trend 2005-2019

Fig. 2, the number of patent filings increased from 2006 itself, interestingly ESTs from 2010 growth noticed with an average annual growth rate over $60 \%$. In the year 2016 ESTs registered 19 applications. Collaboration in ESTs is inconsistent and meager to IITs collaboration. We observe universities and IITs are in the same phase of filing. Green inventory classified environmentally sound technologies under seven categories.

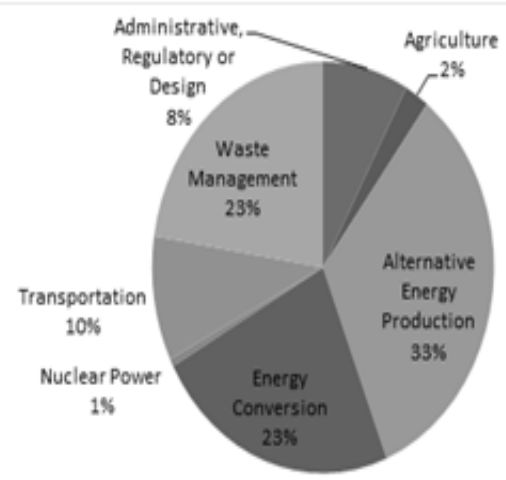

Fig. 3: Proportion of IITs Environmentally Sound Technologies

Fig.3, infer IITs majorly filed alternative energy production technologies $33 \%$ followed by waste management and energy conservation with each $23 \%$ of filing. Compared to earlier fields transportation $10 \%$, administrative regulatory or design $8 \%$ are proportionately less. Agriculture/forestry and nuclear power related ESTs are less than $2 \%$. 


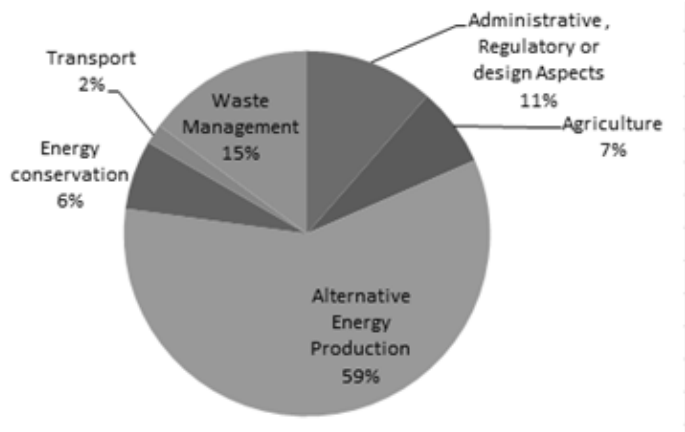

Fig. 4: Proportion of University's Environmentally Sound Technologies

Fig 4. Represent ESTs patent filings of universities, the significant chunk dominated by alternative energy production $59 \%$ followed by waste management technologies $15 \%$ and administrative, regulatory or design aspects $11 \%$ agriculture/forestry technologies and energy conservation has over $6 \%$ of proportionate filings. Least area of technology filings areas are transport $2 \%$ and nuclear power-related technologies were rarely filed. Universities focus on alternative energy production and waste management technologies, whereas IITs perform majorly on alternative energy production, energy conservation and waste management. However, other fields are concentrated fewer.

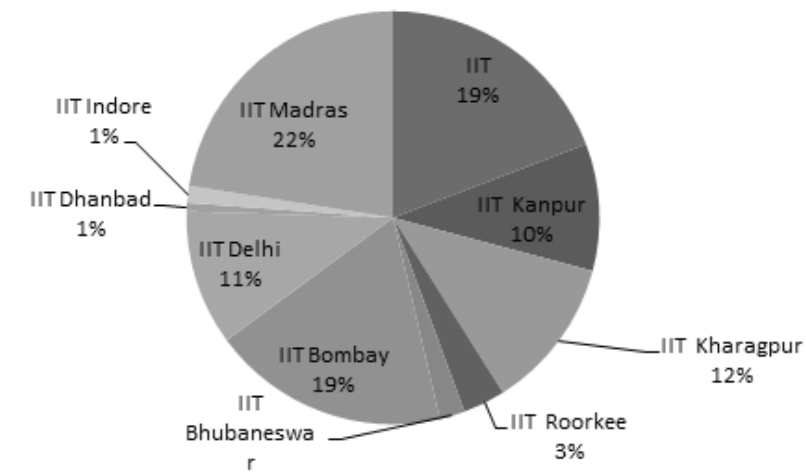

Fig 5: Proportion of Top IITs Applicants of ESTs

From fig 5, out of 23 IITs only 9 are active, IIT Madras observed as top applicants of ESTs with $22 \%$ of filings followed by IIT Bombay $19 \%$ and IITs that are unidentified to label 19\%. IIT Kharagpur, IIT Delhi and IIT Kanpur registered more or less equal contributions are over $10 \%$. However, the rest of the IITs filing is limited.

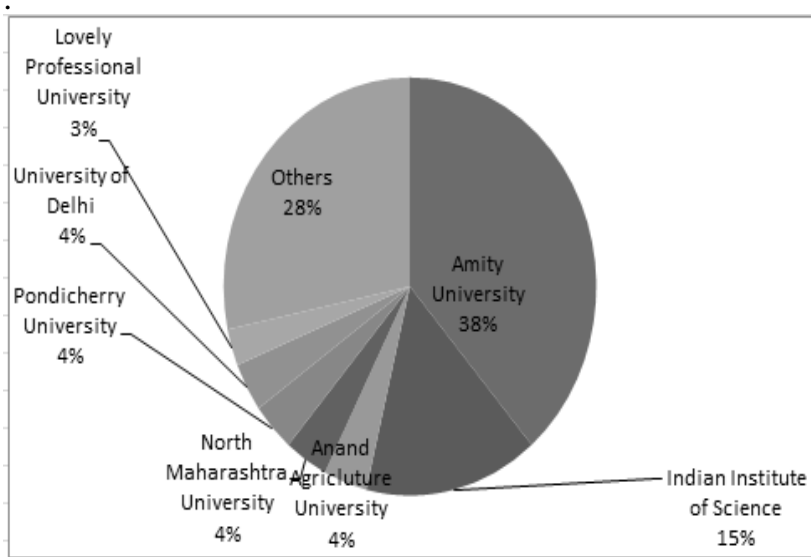

Fig 6: Proportion of Top University Applicants of ESTs
Amity University, a private institution dominated other universities in ESTs filings with $38 \%$ as compared to 26 universities as in fig. 6 . Followed by $15 \%$ contributed by a deemed university. i.e. Indian Institute of Science (IISc). University of Delhi, Anand Agricultural University, Pondicherry University, Lovely Professional University merely contributed over $3 \%$, whereas other universities filed less than $2 \%$ patents.

Fig. 7, there are 244 collaboration relationship made with IITs by other actors such as enterprise $44 \%$ followed by research institutions $17 \%$, government $17 \%$. Here the government entails departments under ministries e.g. Department of Science and Technology (DST) and 6\% of Government organizations like Defense Research and Development Organization (DRDO). Less connection exists between other IITs, Individuals and NGO.

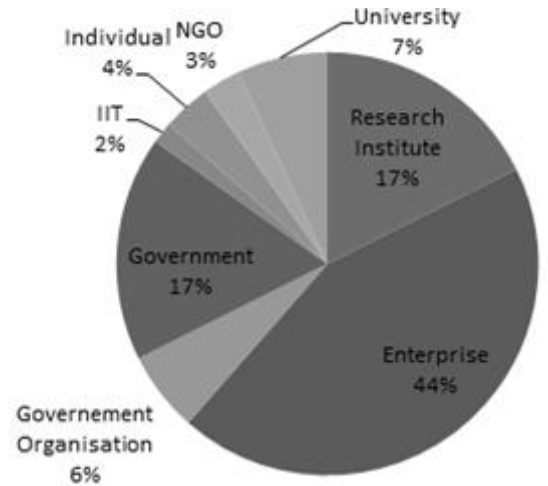

Fig 7: IITs Collaboration Relationship with other actors

Fig 8: patent collaboration network of IITs has an average path length of 3.453 which is smaller to random generated network's 4.69 average path lengths, showing the knowledge transfer in the network is good. Network density is 0.019 show less density and average cluster coefficient patent collaboration network is 0.099 which is more than random generated network 0.063. Overall, the result shows IITs patent collaboration network is a small-world network [26].

Degree centrality measure specifies a large collaboration with another node. From table 1, we infer IIT Bombay, IIT Madras, IIT Delhi and IIT Kharagpur have a larger interaction with others and relatively hold key positions. Betweenness centrality shows a high proportion of interconnection with other vectors or nodes; IIT Bombay, IIT Madras, IIT Delhi and Department of Biotechnology(DBT) are inter-connectors between other nodes; they have more channel advantage in exchange of knowledge or technology. Closeness centrality measure closeness with other nodes and hold the vital area in the network, IIT Jodhpur, two individuals, DBT and Department of Electronics and Information Technology (DeITY) has influence amongst IITs. Eigenvector measures good relationship with neighbors thus from table 1, IIT Madras, IIT Bombay, DBT, IIT Delhi are important nodes and has a good interaction with important neighboring nodes, thus expose strong alliance. 


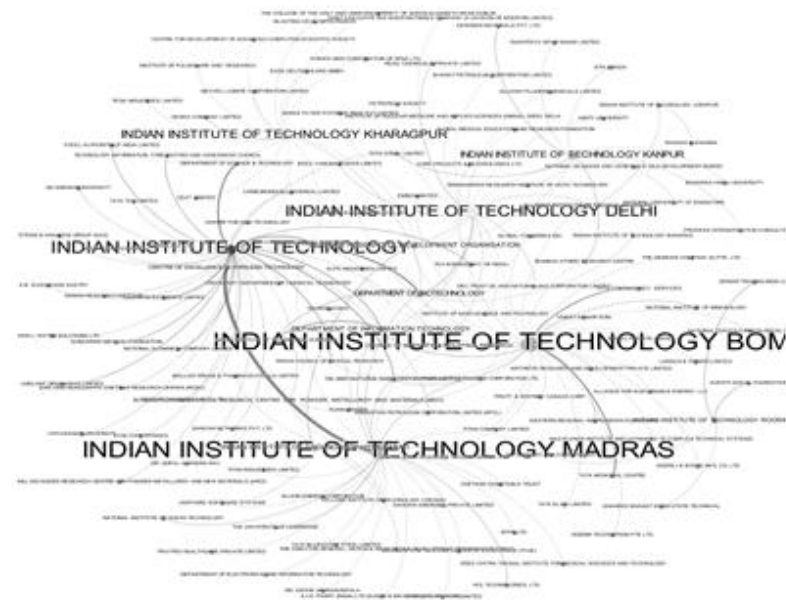

Fig. 8: Patent Collaboration Network of IITs

Table 1: Top 5 Important Nodes of IIT Collaboration Network

\begin{tabular}{|l|l|l|l|}
\hline $\begin{array}{l}\text { Degree } \\
\text { centrality }\end{array}$ & $\begin{array}{l}\text { Betweenness } \\
\text { centrality }\end{array}$ & $\begin{array}{l}\text { Closeness } \\
\text { centrality }\end{array}$ & $\begin{array}{l}\text { Eigenvector } \\
\text { Centrality }\end{array}$ \\
\hline IIT & IIT & IT Jodh & IIT \\
\hline IITBom & IITBom & $\begin{array}{l}\text { Vineet kumar } \\
\text { soni }\end{array}$ & IITMad \\
\hline IITMad & IITMad & $\begin{array}{l}\text { Rakesh k } \\
\text { sharma }\end{array}$ & IITBom \\
\hline IITDel & IITDel & DBT & DBT \\
\hline IITKhar & DBT & DeITY & IITDel \\
\hline
\end{tabular}

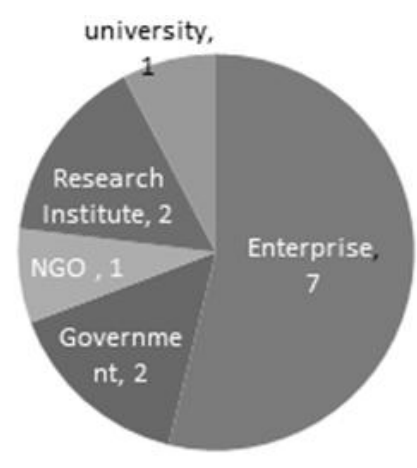

Fig.9: IITs Collaboration Relationship for ETSs

Fig.9, represent the IITs number of relationship with other collaborative actors, various enterprises (7) like public, private companies and public sector undertaking were included. We considered government departments as government. IIT Madras, IIT Kharagpur, IIT Roorkee, and IIT Bombay are the institutions handled collaborations.

Overall, universities have established 314 collaborative relationships with other actors. Fig 10, universities have collaborated mainly with Government departments 27\%, enterprise $19 \%$, other universities $19 \%$ and research institutes $18 \%$. However, collaboration with Government organisation $8 \%$, individual $6 \%$, IITs $2 \%$ and NGO $1 \%$ are relatively less.

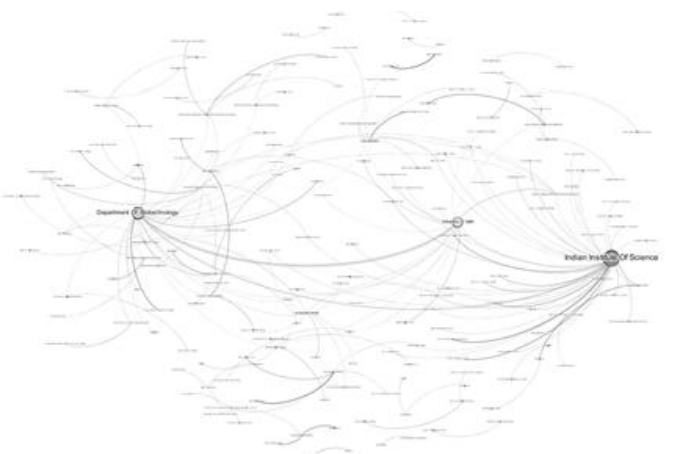

Fig.11: Patent Collaboration Network of Univesities

Fig.11, the average path length of university collaboration network is 3.442 which are smaller to random generated the network of 3.926 average path lengths show the knowledge transfer in the network is good. Network density is 0.011 , which indicate less density and average cluster coefficient of patent collaboration network is 0.057 that is more than random generated a network of 0.014 .

Overall, the result indicates a small-world network. Based on Degree of centrality from table 2. IISc, DBT, University of Delhi, Jawaharlal Nehru University and the University of Calcutta registered significant collaboration relationship with other nodes. Betweenness centrality of table 2 illustrates the DBT, IISc, Delhi University, Indian Council of Medical Research (ICMR) and Shavitri Bhai Phule University has a high proportion of paths between other nodes. Panjab University, two individuals, Karpagam University and Delhi University are the players of the central network. Whereas DBT, IISc, Delhi University, Jawaharlal Nehru University (JNU) and Council of Scientific and Industrial Research (CSIR) are important players connected other important players.

Table 2: Top 5 Important Nodes of University Collaboration Network for ETSs

\begin{tabular}{|l|l|l|l|}
\hline $\begin{array}{l}\text { Degree } \\
\text { centrality }\end{array}$ & $\begin{array}{l}\text { Betweennes } \\
\text { s centrality }\end{array}$ & Closeness centrality & $\begin{array}{l}\text { Eigenvecto } \\
\text { r centrality }\end{array}$ \\
\hline IIsc & DBT & Panjab Uni & DBT \\
\hline DBT & IISC & VK Gopalakrishnan & IISC \\
\hline Delhi uni & Delhi uni & Gurukumar & Delhi uni \\
\hline JNU & ICMR & Kapagam Uni & JNU \\
\hline Uni Cal & $\begin{array}{l}\text { Savitribai un } \\
\text { i }\end{array}$ & Del Tech Uni & CSIR \\
\hline
\end{tabular}

Universities collaborated majorly with DBT (6) fig.12. University of Delhi, Pondicherry University, Amity University, Indian Institute of Science, University of Calcutta, Jawaharlal Nehru University and Anand Agricultural University collaborate university mostly with Department of Bio-Technology. 


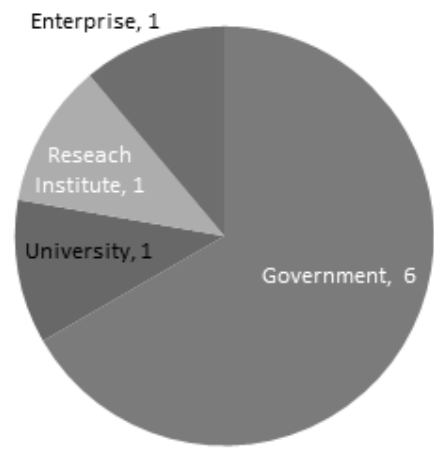

Fig 12 : University Collaboration Network for ESTs

\section{CONCLUSION}

With special reference to environmentally sound technologies, using visualization techniques we analyzed patents filing trends, technology proportions, top applicants, collaborative relationships and important nodes in collaborative networks of IITs and Indian universities from patentscope database and environmental codes taken from green patent inventory of WIPO, for the period 2005 to 2019. A data visualization tools are adapted to present the results, the study covered 930 institutions out of which only 35 institutions are part of producing ESTs patents.

Regarding patent activity compared to other technology filings, ESTs patents filings are just $6 \%$ recorded in both IITs and Universities in 14 years. This level of activity is at rock bottom, over the years' inferior growth on ESTs continues. At the technological level we found the course of ESTs, Out of ESTs categories created under green patent inventory alternative energy production, energy conservation and waste management are much concentrated by IITs. However, more than Half of ESTs filing from universities is alternative energy production which may be because of scientific specializations and infrastructures.

At, institutions level only 35 are found to be active players i.e. 26 universities and 9 IITs filed ESTs patents. IIT Madras, IIT Bombay, IIT Kharagpur, IIT Delhi, IIT Kanpur are major players. However, IIT Bhubaneswar, IIT Roorkee, IIT Indore and IIT Dhanbad proportions on ETSs are very less. Amity University holds over one-third of ESTs followed by IISc, which are the key actors. Universities such as Anand Agricultural University, University of Delhi, Lovely Professional University, Pondicherry University and North Maharashtra University proportions are meager.

IITs mostly collaborated with enterprises, universities and with Government like Department of Biotechnology. Important players in collaborative network are IIT Jodhpur, IIT Madras, IIT Bombay, IIT Delhi, Department of Biotechnology, IIT Kharagpur, Department of Electronics and Information Technology. However, in the case of ESTs, IITs have collaboration with enterprises i.e. Coassignees. On flip side IISc, Department of Biotechnology, Panjab University, University of Delhi, JNU, ICMR, Karpagam University, University of Calcutta, Savitribai Phule Pune University, Delhi Technological University and Council of Scientific and Industrial Research hold a major part in university collaboration segment.

For ESTs universities majorly collaborated with Department of Biotechnology, Central Power Research Institute, JNU, IISc, Pondicherry University, Amity University, Anand Agricultural University, University of Calcutta and University of Delhi.
In conclusion, overall patent filing is increased significantly; however, higher education institution sensibility towards research for sustainable development is weak and much weaker for Collaboration. Higher education institutions research progress has isolated itself from vision third mission of interaction with industry, Government and society for marking impression on sustainability science is debatable. Rethinking third mission for extending its boundary for research and embracing it to attain sustainable developmental goals is vital and evolving one. The innovation agenda should be skewed towards sustainability and sustainable collaboration in future for various green technological fields. Overall patent filing on technologies for sustainable development is yet to be tapped into by Indian higher education institutions for better opportunities to add value to the third mission.

\section{REFERENCES}

1. Wright, T. (2004). The evolution of sustainability declarations in higher education. In Higher education and the challenge of sustainability (pp. 7-19). Springer, Dordrecht.

2. McMichael A, Butler C, Folke C. New visions for addressing sustainability.Science 2003;302:1919-20.

3. Gallopín, G. C., Funtowicz, S., O'Connor, M., \& Ravetz, J. (2001). Science for the twenty-first century: from social contract to the scientific core. International Social Science Journal,53(168), 219-229

4. Sharma, B. (2014). Sustainable development through research and higher education in India. American Journal of Educational Research, 2(3), 117-122.

5. International Energy Agency. (2007). Key world energy statistics (p. 6). Paris: International Energy Agency.

6. Fadeeva, Z., \& Mochizuki, Y. (2010). Higher education for today and tomorrow: university appraisal for diversity, innovation and change towards sustainable development. Sustainability Science, 5(2), 249-256.

7. Hagen, R. (2002). Globalization, university transformation and economic regeneration: A UK case study of public/private sector partnership. International Journal of Public Sector Management, 15(3), 204-218.

8. Joshi, S., \& Gupta, P. (2013). How India innovates: the promise of sustainable \& inclusive innovation. cII-ITc centre of Excellence for Sustainable Development. Available: https://www.sustainabledevelopment.in/uploads/pdf/1445612436Ho w_India_Innovates 2013.pdf.

9. Etzkowitz, Henry, Andrew Webster, Christiane Gebhardt, and Branca Regina Cantisano Terra. "The future of the university and the university of the future: evolution of ivory tower to entrepreneurial paradigm." Research policy 29, no. 2 (2000): 313-330.

10. Siegel, D., Waldman, D., \& Link, A. (2003a). Assessing the impact of organizational practices on the relative productivity of university technology transfer offices: An exploratory study. Research Policy, 32, $27-48$.

11. Bramwell, A., \& Wolfe, D. A. (2008). Universities and regional economic development: The entrepreneurial University of Waterloo. Research policy, 37(8), 1175-1187.

12. Rupinder. T \& Mamta .Bj (2018), Industry-Academia R\&D Ecosystem in India an evidence based study. Publication Bureau, Panjab University. .Available: http://cpr.puchd.ac.in/wp-content/uploads/2017/05/Industry-Academi a-RD-Ecosystem-in-India.pdf

13. Rupinder. T \& Mamta .Bj (2018), Mapping Patents and Research Publications of Higher Education Institutes and National R\&D Laboratories of India. Publication Bureau, Panjab University. Available:

http://www.dst.gov.in/sites/default/files/FULL\%20BOOK-Chandigar $\underline{\text { h.pdf }}$ 


\section{Does the University Third Mission Entail Sustainability Science: Evidence from Indian Higher Educational Institutions' Sustainable Technological Patenting Activity and Collaborations}

14. Sharma, R., \& Jain, A. (2014). Research and patenting in Indian universities and technical institutes: An exploratory study. World Patent Information, 38, 62-66.

15. Waas, T., Verbruggen, A., \& Wright, T. (2010). University research for sustainable development: definition and characteristics explored. Journal of cleaner production, 18(7), 629-636.

16. Lozano, R., Ceulemans, K., Alonso-Almeida, M., Huisingh, D. Lozano, F. J., Waas, T., ... \& Hugé, J. (2015). A review of commitment and implementation of sustainable development in higher education: results from a worldwide survey. Journal of Cleaner Production, 108, $1-18$.

17. Kajikawa Y. Research core and framework of sustainability science. SustainabilityScience 2008;3:215-39.

18. Zawdie, G. (2010). Knowledge exchange and the third mission of universities: Introduction: The triple helix and the third mission-Schumpeter revisited. Industry and Higher Education, 24(3), 151-155.

19. Zomer, A., \& Benneworth, P. (2011). The rise of the university's third mission. In Reform of higher education in Europe (pp. 81-101) SensePublishers.

20. Baldini, N. (2006). University patenting and licensing activity: a review of the literature. Research evaluation, 15(3), 197-207.

21. Baldini, N. (2010). Do royalties really foster university patenting activity? An answer from Italy. Technovation, 30(2), 109-116.

22. Ray, A. S., \& Saha, S. (2010). Drivers of Academic Research and Patenting in India: Econometric Estimation of the Research Production Function (No. 247). Working Paper.

23. Bedi, N., Bedi, P. M. S., \& Sooch, B. S. (2013). Patenting and R\&D in Indian pharmaceutical industry: post-TRIPS scenario

24. Karki, M. M. S., \& Garg, K. C. (1993). Patenting activity in the third world - a case study of biotechnology patents filed in India. World Patent Information, 15(3), 165-170.

25. Lorena. R, León, Kyle, Bergquist, Sacha Wunsch, V. N., Kunihiko. F.,(2015). "Measuring innovation in energy technologies: green patents as captured by WIPO's IPC green inventory", Economic Research Working Paper No. 44. WIPO.

26. Liu, W., Tao, Y., Yang, Z., \& Bi, K. (2019). Exploring and Visualizing the Patent Collaboration Network: A Case Study of Smart Grid Field in China. Sustainability, 11(2), 465.

27. Ryan Jr, C. J., \& Frye, B. L. (2017). An Empirical Study of University Patent Activity. NYU J. Intell. Prop. \& Ent. L., 7, 51.

28. Cesaroni, F., \& Piccaluga, A. (2002, March). Patenting Activity of European Universities. Relevant? Growing? Useful?. In conference 'Rethinking Science Policy: Analytical Frameworks for Evidence-Based Policy (pp. 21-23).

29. Henderson, R., Jaffe, A. B., \& Trajtenberg, M. (1998). Universities as a source of commercial technology: a detailed analysis of university patenting, 1965-1988. Review of Economics and statistics, 80(1), 119-127.

30. Johnstone, N., Haščič, I., \& Popp, D. (2010). Renewable energy policies and technological innovation: evidence based on patent counts. Environmental and resource economics, 45(1), 133-155

31. Oldham, P.(2016). The WIPO Manual on Open Source Patent Analystics. Available: https://wipo-analytics.github.io/

32. WIPO.(2018). Patent Scope :The User's Guide. R . Available: https://patentscope.wipo.int/search/en/help/users_guide_summer2018 .pdf

33. University Grand Commission., (2019). total No. of Universities in the Country as on 31.12.2019. Available https://www.ugc.ac.in/oldpdf/Consolidated $\% 20$ list $\% 20$ of $\% 20$ All $\% 20$ Universities.pdf

34. WIPO. (2012). IPC Green Inventory. Available: https://www.wipo.int/classifications/ipc/en/green inventory/

35. MHRD. (2018). All India survey on higher education 2017-18.

36. Ankrah, S., \& Omar, A. T. (2015). Universities-industry collaboration: A systematic review. Scandinavian Journal of Management, 31(3), 387-408

37. M. E. J. Newman. A measure of betweenness centrality based on random walks. Cornell University Library arXiv:condmat/ 0309045 , pages $1-15,2003$.

38. D’Souza, R. J., \& Jose, J. (2011). Significance of eigenvector centrality for routing in a delay tolerant network. Journal of Computations \& Modelling, 1(1), 91-100.43

39. Ni, C., Sugimoto, C., \& Jiang, J. (2011, July). Degree, closeness, and betweenness: Application of group centrality measurements to explore macro-disciplinary evolution diachronically. In Proceedings of ISSI (pp. 1-13).2011.

40. Sharma, P., \& Tripathi, R. C. (2017). Patent citation: A technique for measuring the knowledge flow of information and innovation. World Patent Information, 51, 31-42.
41. Corcoran, P. B., \& Wals, A. E. (2004). The problematics of sustainability in higher education: an introduction. In Higher education and the challenge of sustainability (pp. 3-6). Springer, Dordrecht.

42. Montesinos, P., Carot, J. M., Martinez, J. M., \& Mora, F. (2008). Third mission ranking for world class universities: Beyond teaching and research. Higher education in Europe, 33(2-3), 259-271.

43. Sharma, R., \& Jain, A. (2014). Research and patenting in Indian universities and technical institutes: An exploratory study. World Patent Information, 38, 62-66.

44. Clark, W. C., \& Dickson, N. M. (2003). Sustainability science: the emerging research program. Proceedings of the national academy of sciences, 100(14), 8059-8061.

45. Trencher, G., Yarime, M., McCormick, K. B., Doll, C. N., \& Kraines, S. B. (2013). Beyond the third mission: Exploring the emerging university function of co-creation for sustainability. Science and Public Policy, 41(2), 151-179.

46. Khokhar, D. (2015). Gephi cookbook. Packt Publishing Ltd.

47. Higher education for sustainable development: a systematic review, International Journal of Sustainability in Higher Education Vol. 17 Issue: 5, pp.633-651

\section{AUTHORS PROFILE}

Lourden Selvamani V is a UGC-JRF qualified Senior Research Scholar of

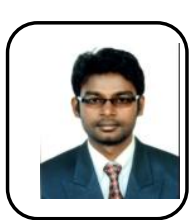
Pondicherry University. He holds Master of Commerce and currently pursues PhD in Intellectual Property Rights and university third mission from Department of International Business. Previously He worked as a Project Assistant for Department of Science and Technology Sponsored research Project title "Developing a Model to Commercialize Intellectual Properties in Indian Universities" handled by Dr. P. G. Arul.

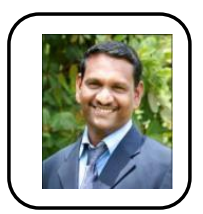

Dr. P. G. Arul is currently serving as Professor at Pondicherry University. He has published books and contributed more than 30 chapters for various books. He has so far completed four research projects sponsored by various government agencies such as Department of Science and Technology, The Indian Council of Social Science Research and University Grants Commission. His area is mainly on International Trade and Logistics, International Human Resource Management, International Marketing and Advertising and International Management Practices. As of now he organized more than 20 conferences/workshops. Currently he is a member in board of studies for other sister departments of commerce. 